\title{
Dumping Syndrome
}

National Cancer Institute

\section{Source}

National Cancer Institute. Dumping Syndrome. NCI Thesaurus. Code C2994.

A disorder of the gastrointestinal tract. It is typically caused by the rapid emptying of undigested food from the stomach to the small intestine following gastroesophageal surgery but may be seen secondary to diabetes or the use of certain medications. Clinical signs may be seen 30-60 minutes after eating (early dumping): cramping, nausea, vomiting and diarrhea or they may be seen 1-3 hours later as a result of hyperinsulinemic hypoglycemia (late dumping): sweating, dizziness, confusion and heart palpitations. Untreated, the clinical course progresses to malnutrition and weight loss. 